\title{
Neoproterozoic Zimmi diamond formation through infiltration of recycled methane into sulphide-bearing Archaean eclogite
}

\author{
Karen V. Smit ${ }^{1}$, Steven B. Shirey ${ }^{2}$, Erik H. Hauri ${ }^{2}$, Jianhua Wang ${ }^{2}$, Thomas Stachel ${ }^{3}$ \\ and Richard A. Stern ${ }^{3}$ \\ ${ }^{1}$ Gemological Institute of America, New York City, NY, USA, ksmit@gia.edu \\ ${ }^{2}$ Department of Terrestrial Magnetism, Carnegie Institution for Science, Washington, DC USA, \\ sshirey@carnegiescience.edu, ehauri@carnegiescience.edu,jwang@carnegiescience.edu \\ ${ }^{3}$ Canadian Centre for Isotopic Microanalysis, University of Alberta, Edmonton, AB, Canada, \\ tstachel@ualberta.ca,rstern@ualberta.ca
}

\section{Introduction}

Sulphide-bearing alluvial diamonds from Zimmi on the Man Shield (West African Craton) have provided an unparalleled opportunity to evaluate eclogitic diamond formation processes. Through high precision analyses of multiple isotopes (Re-Os, $\delta^{13} \mathrm{C}, \delta^{33} \mathrm{~S}, \delta^{34} \mathrm{~S}, \delta^{36} \mathrm{~S}$ ) we are able to determine: 1) the timing of Zimmi eclogitic diamond formation and whether there is any link with local tectonic processes, 2) the genetic relationship between eclogitic sulphide inclusions and diamond-forming fluids (i.e., whether these sulphides were pre-exisiting or rather co-precipitated from the carbonbearing fluids), 3) the implications for the interpretation of isotopic diamond ages, and 4) the redox speciation of fluids likely released during Neoproterozoic subduction, and whether they participated in diamond formation through redox processes or isochemical cooling.

\section{Neoproterozoic ages for Zimmi eclogitic diamonds}

Ten pyrrhotite-rich eclogitic sulphides encapsulated in three Zimmi diamonds have Re-Os isotopic compositions that plot along three $650 \mathrm{Ma}$ age arrays (Figure 1; Smit et al., 2016). Each of the three diamonds records identical absolute ages, with distinct initial ${ }^{187} \mathrm{Os} /{ }^{188} \mathrm{Os}$ between 1.5 and 2.2. These three $650 \mathrm{Ma}$ diamond ages overlap with the timing of continental assembly through subduction recorded in the Rokelide orogen along the southwestern margin of the West African craton (700-550 Ma; Lytwyn et al., 2006).
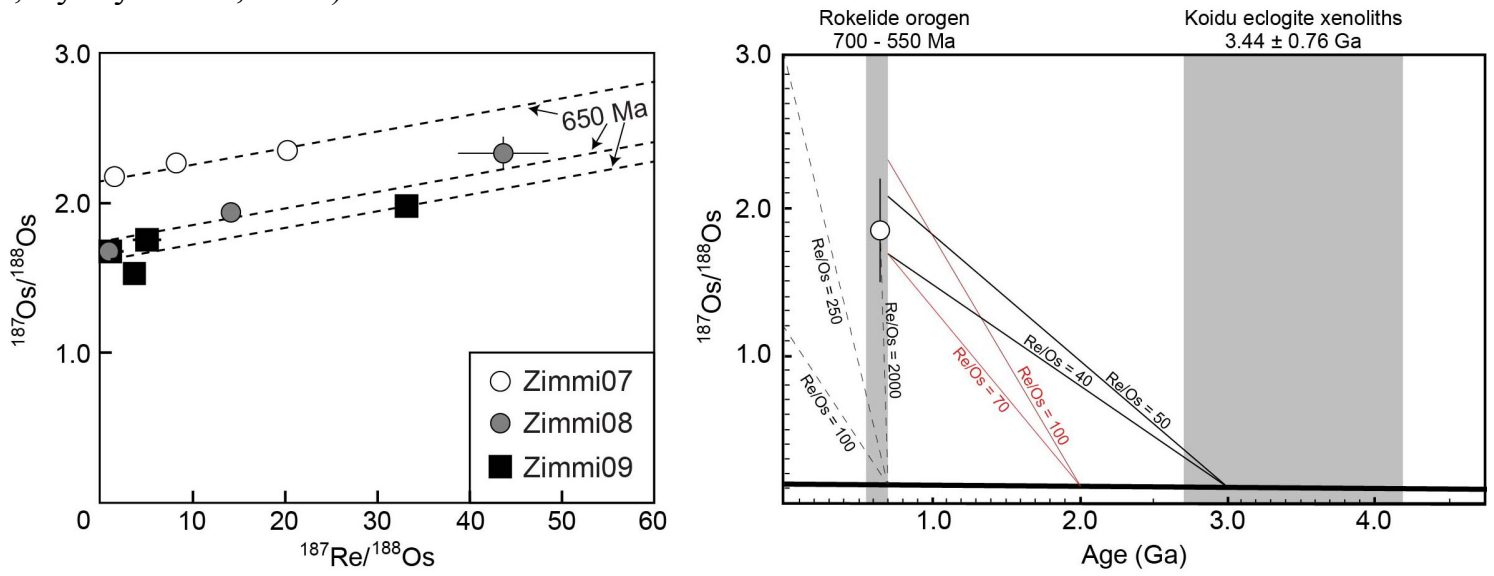

Figure 1: Ten pyrrhotite-rich eclogitic sulphides in three different Zimmi diamonds record identical Re-Os absolute ages of $650 \mathrm{Ma}$. Initial ${ }^{187} \mathrm{Os} /{ }^{188} \mathrm{Os}$ ratios of 1.5 to 2.2 are too radiogenic to be derived from Neoproterozoic oceanic crust, but could evolve from enriched Archaean reservoirs in the lithosphere that have $\mathrm{Re} / \mathrm{Os}$ around 40-50.

\section{Evidence from Re-Os for pre-existing sulphides}

All ten sulphides have radiogenic Os isotopic compositions that are not supported by their low Re/Os ratios, requiring some Re loss prior to or at the time of diamond formation. This confirms that the 
sulphides and diamond-source fluids/melts cannot share a single-stage origin. Furthermore, initial ${ }^{187} \mathrm{Os} /{ }^{188} \mathrm{Os}$ ratios for the age arrays in three diamonds are all very radiogenic $\left({ }^{187} \mathrm{Os} /{ }^{188} \mathrm{Os}\right.$ between 1.5 to 2.2), relative to the chondritic mantle at $650 \mathrm{Ma}(0.124$; Figure 1), indicating that unlike the diamond-forming fluids, the sulphides did not originate in Neoproterozoic oceanic crust. Rather, the radiogenic ${ }^{187} \mathrm{Os} /{ }^{188} \mathrm{Os}$ initial ratios indicate the sulphides' residence in an enriched lithospheric reservoir. In the West African lithospheric mantle, such enriched reservoirs could be represented by Archaean eclogites, such as those from the Koidu kimberlite (Barth et al., 2002). With Re/Os ratios around 40-50 such eclogites could evolve to radiogenic ${ }^{187} \mathrm{Os} /{ }^{188} \mathrm{Os}$ recorded in Zimmi sulphides over 2 billion years (Figure 1).

\section{Evidence from multiple sulphur isotopes for an Archaean sulphur source}

An Archaean source of sulphur for the inclusions in Neoproterozoic Zimmi diamonds was tested through in situ multiple sulphur isotope analyses by NanoSIMS (Hauri et al., 2016), using methods similar to those described for the 1280 ion microprobe (Whitehouse et al., 2013). Preliminary data on three sulphide inclusions in three different diamonds, have a wide range of $\delta^{34} \mathrm{~S}$ values, between -1 and $-6 \%$, all outside of the typical mantle value and consistent with a crustal sulphur reservoir. All three sulphides have $\delta^{33} \mathrm{~S}$ and $\delta^{36} \mathrm{~S}$ values that deviate from the arrays that define mass dependent fractionation $\left(\delta^{33} \mathrm{~S}=0.5167 \times \delta^{34} \mathrm{~S}\right.$ and $\left.\delta^{36} \mathrm{~S}=1.9 \times \delta^{34} \mathrm{~S}\right)$. Expressed as $\Delta^{33} \mathrm{~S}$ and $\Delta^{36} \mathrm{~S}$, these deviations are due to mass independent fractionation (MIF), a process commonly understood to only occur in the Archaean oxygen-deprived atmosphere (Farquhar et al., 2000). Zimmi sulphides have $\Delta^{33} \mathrm{~S}$ between +0.3 and $+1.7 \%$ and $\Delta^{36} \mathrm{~S}$ between -0.7 and $-2.5 \%$ that plot along the array for Archaean metasediments (Figure 2). Importantly, MIF of sulphur isotopes in Zimmi sulphides indicate that sulphur could not have been solely derived from Neoproterozoic oceanic crust. Rather, these MIF signatures support the Re-Os evidence for sulphur residence in an Archaean enriched reservoir prior to encapsulation in diamond.

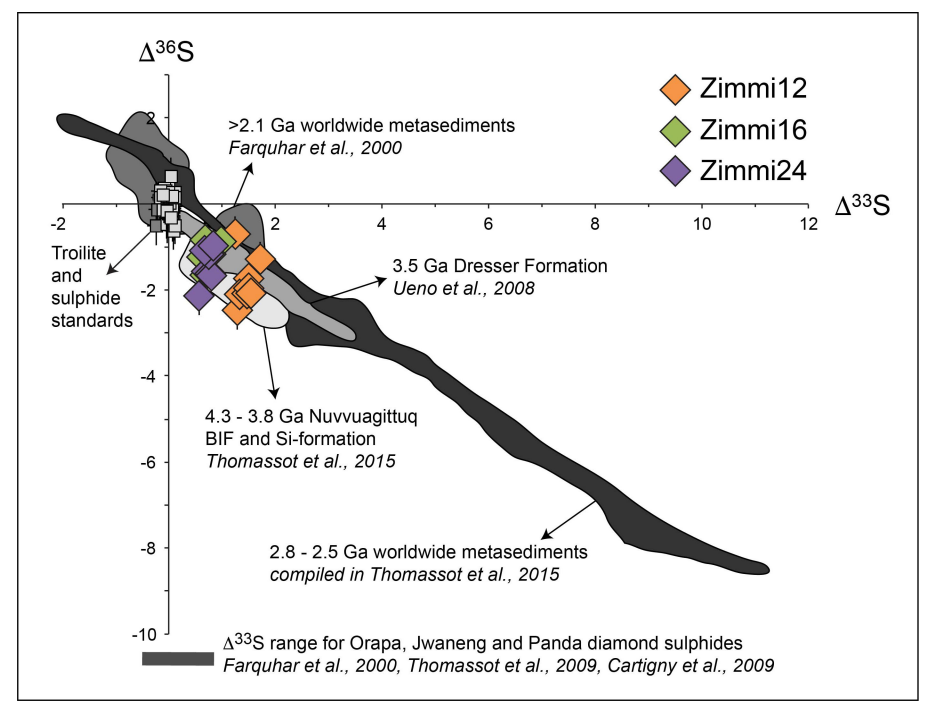

Figure 2: Preliminary NanoSIMS sulphur isotope data for three Zimmi sulphide inclusions compared to Archaean metasediments from the literature. MIF sulphur isotopes only originate during the Archaean, suggesting that carbon and sulphur in Zimmi diamonds and their inclusions do not share a common origin in Neoproterozoic oceanic crust. Error bars for Zimmi sulphides are similar to the symbol size.

\section{Recycled carbon source for diamond-forming fluids}

Carbon isotopic compositions for 5 diamonds from Zimmi range between -6.5 and $-24.5 \%$. $\delta^{13} \mathrm{C}$ values below $-10 \%$ are outside the range for mantle carbon and require derivation from subducted oceanic crust. The presence of recycled carbon in Zimmi diamonds is consistent with the timing of diamond formation derived from the Re-Os isotope data and Neoproterozoic subduction in the West 
African Craton. $\delta^{13} \mathrm{C}$ values for Zimmi diamonds that overlap with the mantle value could represent carbon derived from the convecting mantle, however a recycled origin for these mantle-like values cannot be excluded as they could be indicative of abiogenic carbon contributions from the oceanic crust.

\section{Diamond precipitation during oxidation of methane}

In eclogitic assemblages, diamond formation processes through either redox buffering or cooling of carbon-bearing fluids are not well constrained. In one Zimmi diamond, a core-to-rim trend of gradually decreasing $\delta^{13} \mathrm{C}(-23.4$ to $-24.5 \%)$ and $\mathrm{N}$-content is indicative of formation from reduced $\mathrm{CH}_{4} \pm \mathrm{C}_{2} \mathrm{H}_{6}$ fluids, likely derived from oceanic crust recycled during Neoproterozoic subduction. Unlike mixed $\mathrm{CH}_{4}-\mathrm{CO}_{2}$ fluids near the $\mathrm{H}_{2} \mathrm{O}$-maximum, isochemical cooling of such reduced fluids is only efficient during ascent (Stachel and Luth, 2015) and therefore cannot explain smooth compositional trends within individual diamonds residing at constant pressure (documented here). Consequently, this Zimmi eclogitic diamond likely formed through redox buffering of reduced subduction-related fluids, infiltrating into sulphide-bearing eclogite.

\section{Growth conditions for Zimmi eclogitic diamonds}

Neoproterozoic Zimmi eclogitic diamonds formed during infiltration of carbon-bearing fluids that can be temporally linked to local subduction that introduced oceanic crust and its carbon budget into the lithospheric keel. The wide range in $\delta^{13} \mathrm{C}$ values recorded by five diamonds indicate multiple carbon sources in the oceanic crust that include $\mathrm{CH}_{4}-\mathrm{C}_{2} \mathrm{H}_{6}$ with $\delta^{13} \mathrm{C}$ around $-24 \%$. At least one Zimmi diamond formed during oxidation of this reduced recycled carbon when it infiltrated into the Archaean lithosphere. Our Re-Os, $\Delta^{33} \mathrm{~S}$ and $\Delta^{36} \mathrm{~S}$ data require that, unlike carbon, sulphur was not solely derived from Neoproterozoic sources. Rather, at least some of the sulphur in Zimmi sulphide inclusions resided in the enriched Archaean lithosphere prior to encapsulation in Neoproterozoic diamonds. This unequivocally demonstrates that multiple pre-existing sulphides can record diamond ages if their Re-Os isotopes diffuse and re-equilibrate during diamond formation. This is expected during eclogitic diamond formation since PT conditions for worldwide eclogitic diamond inclusions indicate formation in partially molten conditions above $1100{ }^{\circ} \mathrm{C}$ (Stachel and Luth, 2015), significantly above the closure temperature for Re-Os exchange in pyrrhotite $\left(400{ }^{\circ} \mathrm{C}\right.$; Brenan et al., 2000).

\section{References}

Barth, M, Rudnick, RL, Carlson, RW, Horn, I, McDonough, WF (2002) Re-Os and U-Pb geochronological constraints on the eclogite-tonalite connection in the Archean Man Shield, West Africa. Precamb Res, 118, 267-283

Brenan, JM, Cherniak, DJ, Rose, LA (2000) Diffusion of osmium in pyrrhotite and pyrite: implications for closure of the Re-Os isotopic system. EPSL, 180, 399-413

Farquhar, J, Bao, H, Thiemens, M (2000) Atmospheric Influence for Earth's Earliest Sulfur Cycle. Science, 289, 756-758

Hauri, EH, Papineau D, Wang, J, Hillion, F (2016) High-precision analysis of multiple sulfur isotopes using NanoSIMS. Chem Geol, 420, 148-161

Lytwyn, J, Burke, K, Culver, S (2006) The nature and location of the suture zone in the Rokelide orogen, Sierra Leone: geochemical evidence. Journal of African Earth Science, 46, 439-454

Smit, KV, Shirey SB, Wang, W (2016) Type Ib diamond formation and preservation in the West African lithospheric mantle: Re-Os age constraints from sulphide inclusions in Zimmi diamonds. Precamb Res, 286, 152-166

Stachel, T, Luth RW (2015) Diamond formation - Where, when and how? Lithos, 220-223, 200-220

Whitehouse, MJ (2013) Multiple sulfur isotope determination by SIMS: Evaluation of reference sulfides for $\Delta^{33} \mathrm{~S}$ with observations and a case study on the determination of $\Delta^{36} \mathrm{~S}$. Geostand. Geoanal. Res. 37, 19-33 